\title{
Cadmium-induced autophagy promotes survival of rat cerebral cortical neurons by activating class III phosphoinositide 3-kinase/beclin-1/B-cell lymphoma 2 signaling pathways
}

\author{
QI-WEN WANG ${ }^{1-4^{*}}$, YI WANG $^{1,2^{*}}$, TAO WANG $^{1,2}$, KANG-BAO ZHANG $^{1,2}$, \\ CHENG-YANG JIANG ${ }^{1,2}$, FEI-FEI HU ${ }^{1,2}$, YAN YUAN ${ }^{1,2}$, JIAN-CHUN BIAN ${ }^{1,2}$, \\ XUE-ZHONG LIU ${ }^{1,2}$, JIAN-HONG GU ${ }^{1,2}$ and ZONG-PING LIU ${ }^{1,2}$ \\ ${ }^{1}$ College of Veterinary Medicine, Yangzhou University; \\ ${ }^{2}$ Jiangsu Co-Innovation Center for Prevention and Control of Important Animal Infectious Diseases and Zoonoses, \\ Yangzhou, Jiangsu 225009; ${ }^{3}$ Bijie Pilot Area Research Institute, Guizhou University of Engineering Science, \\ Bijie, Guizhou 551700; ${ }^{4}$ State Key Laboratory Cultivation Base for Cell Differentiation Regulation, \\ Henan Normal University, Xinxiang, Henan 453007, P.R. China
}

Received July 17, 2014; Accepted April 10, 2015

DOI: $10.3892 / \mathrm{mmr} .2015 .3755$

\begin{abstract}
Autophagy is an evolutionarily conserved response that can be activated in response to heavy metal. Thus, the present study investigated the effect of autophagy on neurotoxic damage caused by cadmium $(\mathrm{Cd})$ in rat cerebral cortical neurons. The results indicated that the viability of cortical neurons treated with Cd was markedly decreased in a dose- and time-dependent manner. The present study provided evidence that cortical neurons treated with $\mathrm{Cd}$ underwent autophagy: The conversion of microtubule-associated protein 1A/1B-light chain 3 (LC3) to LC3-II, an increase in the punctate distribution of endogenous LC3-II and the presence of autophagosomes were identified. Combined treatment with $\mathrm{Cd}$ and chloroquine, an autophagy inhibitor, reduced the amount of autophagocytosis and cell activity, whereas rapamycin, an autophagy inducer, reduced Cd-mediated cytotoxicity. Furthermore, it was found that beclin-1 and class III phosphoinositide 3 kinase (PI3K) levels were increased, while levels of the anti-apoptotic protein B-cell lymphoma 2 (Bcl-2) were decreased after $\mathrm{Cd}$ treatment. LY294002, a specific inhibitor of PI3K, prevented the decline in $\mathrm{Bcl}-2$ production and the increase in levels of beclin-1, class III PI3K and autophagy following Cd treatment.
\end{abstract}

Correspondence to: Dr Zong-Ping Liu, College of Veterinary Medicine, Yangzhou University, 88 South University, Yangzhou, Jiangsu 225009, P.R. China

E-mail: liuzongping@yzu.edu.cn

${ }^{*}$ Contributed equally

Key words: cadmium, autophagy, cortical neurons, cytoprotection, beclin-1
In conclusion, the results of the present study suggested that $\mathrm{Cd}$ can induce cytoprotective autophagy by activating the class III PI3K/beclin-1/Bcl-2 signaling pathway, and that the autophagy pathway can serve as a sensitive biomarker for nervous system injury after exposure to $\mathrm{Cd}$.

\section{Introduction}

It is now believed that autophagy has broader importance in regulating growth and maintaining homeostasis in multicellular organisms (1). In the course of autophagy, an isolation membrane forms, which is thought to arise from a vesicular compartment, invaginates and sequesters cytoplasmic constituents to form a double or multimembranous structure, known as the autophagosome. The outer membrane of the autophagosome fuses with the lysosome to deliver the inner membranous vesicle to the lumen of the degradative compartment. Degradation of the sequestered material generates nucleotides, amino acids and free fatty acids that are recycled for macromolecular synthesis and adenosine triphosphate generation (2). At the level of the organism and the cell, autophagy can, paradoxically, have pro-death or pro-survival functions depending on the context. Autophagy mainly has an adaptive role to protect organisms during periods of enhanced cellular distress (3). However, the pro-survival functions of autophagy may be deleterious and lead to cell death, which is termed type II cell death (4).

One of the most-studied mammalian autophagy proteins that falls into the category of vesicle nucleation is beclin-1 (5). Beclin-1 interacts with class III phosphoinositide 3 kinase (PI3K), Vps34, and is involved in autophagic vesicle nucleation. However, under favorable physiological conditions, anti-apoptotic members of the B-cell lymphoma 2 (Bcl-2) family, including Bcl-2 and Bcl-extra large (Bcl-XL), interact with beclin-1 (through the $\mathrm{BH} 3$ domain), thus inhibiting its 
pro-autophagic function $(4,6,7)$. It has been reported that beclin-1 is involved in several other biological functions and in pathological conditions, including heart disease, pathogen infection, development and neurodegeneration (8).

$\mathrm{Cd}$ is a significant toxic and carcinogenic element that is widely present in the environment (9). This heavy metal can cause neurological and behavioral impairment, leading to memory deficits (10), alteration of social contact (11), olfactory dysfunction (12), synaptic function and neurotransmission $(13,14)$. Most studies conducted using cell models have focused on the induction of severe apoptosis and necrosis by $\mathrm{Cd}(15,16)$ and, as a result, the role of autophagy has remained elusive. The present study sought to determine whether autophagy is responsible for the cytotoxicity of $\mathrm{Cd}$ and investigated the mechanisms underlying autophagic pathways in rat cerebral cortical neurons.

\section{Materials and methods}

Materials. $\mathrm{Cd}\left(\mathrm{CH}_{3} \mathrm{COO}\right)_{2} \times 3 \mathrm{H}_{2} \mathrm{O}(\mathrm{Cd})$, poly-L-lysine, chloroquine (CQ), rapamycin (RAP) and MTT were purchased from Sigma-Aldrich (St. Louis, MO, USA). NEUROBASAL ${ }^{\mathrm{TM}}$ medium, B27 supplement and Dulbecco's modified Eagle's medium (DMEM)-F12 (1:1) were purchased from Invitrogen Life Technologies (Carlsbad, CA, USA), while PI3K inhibitor LY294002 (LY). Monoclonal rabbit anti-class III PI3K (cat. no. 3358), anti-Bcl-2 (cat. no. 2870), anti- $\beta$-actin (cat. no. 4970), horseradish peroxidase (HRP)-conjugated goat anti-rabbit (cat. no. 7074) and goat anti-mouse (cat. no. 7056) immunoglobulin ( $\mathrm{Ig}) \mathrm{G}$ antibodies, and fluorescein isothiocyanate (FITC)-conjugated anti-rabbit IgG (cat. no. 4412) were purchased from Cell Signaling Technology, Inc. (Danvers, MA, USA). Monoclonal mouse anti-beclin-1 antibody (cat. no. sc48341) was purchased from Santa Cruz Biotechnology (Dallas, TX, USA). Polyclonal rabbit anti-LC3B antibody (cat. no. L7543) was purchased from Sigma-Aldrich.

Cell isolation and culture. The present study was performed in strict accordance with the recommendations of the Guide for the Care and Use of Laboratory Animals of the National Research Council. All procedures described in the present study were reviewed and approved by the Animal Care and Use Committee of Yangzhou University [Yangzhou, China; approval ID: SYXK (Su) 2007-0005].

Primary cerebral cortical neurons were isolated from 13 embryos removed from pregnant Sprague-Dawley rats (Laboratory Animal Center in Yangzhou University, Yangzhou, China) at 17-18 days of gestation as described previously (17) The cells were used for experiments after five days of culture.

Immunofluorescence. Cortical neuronal cells were seeded at a density of $2.5 \times 10^{5}$ cells $/ \mathrm{ml}$ in six-well plates containing a glass coverslip in each well and treated with 0 or $20 \mu \mathrm{mol} / 1 \mathrm{Cd}$ for 4 or $6 \mathrm{~h}$. After being washed with phosphate-buffered saline (PBS; pH 7.2-7.4), cells were fixed with $4 \%$ paraformaldehyde (Nanjing Jiancheng Bioengineering Institute, Nanjing, China) in PBS for $30 \mathrm{~min}$ at $4^{\circ} \mathrm{C}$. Cells were then permeabilized for 10 min with $0.5 \%$ Triton X-100 (Beijing Solarbio Science \& Technology Co., Ltd., Beijing, China) in PBS and blocked with bovine serum albumin (Beijing Solarbio Science \&
Technology Co., Ltd.) in PBS for 20 min at room temperature. Cells were incubated with anti-LC3B rabbit polyclonal antibody (diluted 1:150) in blocking solution for $2 \mathrm{~h}$ at room temperature, washed in blocking solution and then stained with FITC-conjugated anti-rabbit IgG (diluted 1:200) in blocking solution for $1 \mathrm{~h}$. Cell nuclei were then stained by DAPI (Sigma-Aldrich). After being washed, samples were examined under a fluorescence microscope (Leica DMI 3000B; Leica Microsystems, Wetzlar, Germany).

Electron microscopy. For transmission electron microscopy (TEM), after being treated with 0 and $20 \mu \mathrm{mol} / 1 \mathrm{Cd}$ for $4 \mathrm{~h}$, the cells were trypsinized, collected and centrifuged. The pellets were immediately fixed in ice-cold glutaraldehyde $(2.5 \%$ in $0.1 \mathrm{~mol} / \mathrm{l}$ cacodylate buffer, $\mathrm{pH} 7.4$; Nanjing Jiancheng Bioengineering Institute) for $24 \mathrm{~h}$, and the cells were post-fixed in osmium tetroxide (Tianjing Dengke Chemical Reagent Co., Ltd., Tianjing, China). After dehydration with a graded series of ethanol (Nanjing Jiancheng Bioengineering Institute), the samples were rinsed in propylene oxide (Tianjing Dengke Chemical Reagent Co., Ltd.) and impregnated with epoxy resins (Tianjing Dengke Chemical Reagent Co., Ltd.). The ultrathin sections were contrasted with uranyl acetate and lead citrate (Tianjing Dengke Chemical Reagent Co., Ltd.) for electron microscopy. Electron micrographs were captured using a PHILIPS CM-120 (Philips, Eindhoven, The Netherlands) transmission electron microscope.

Western blot analysis. After treatment, cells were washed twice with cold PBS and extracted using radioimmunoprecipitation lysis buffer (Beijing Solarbio Science \& Technology Co., Ltd.) on ice for $30 \mathrm{~min}$, sonicated for $10 \mathrm{sec}$ and centrifuged at $12,000 \mathrm{x}$ g for $10 \mathrm{~min}$ at $4^{\circ} \mathrm{C}$. The protein content was determined using a bicinchoninic acid protein assay kit (Beyotime Institute of Biotechnology, Shanghai, China). Lysates were diluted with 6X SDS sample buffer (Beijing Solarbio Science \& Technology Co., Ltd.) and boiled for $10 \mathrm{~min}$. Equal amounts of protein were separated using 12-15\% SDS-PAGE and transferred onto nitrocellulose membranes (Beijing Solarbio Science \& Technology Co., Ltd.). After being blocked at room temperature with 5\% non-fat milk in Tris-buffered saline with $0.1 \%$ Tween-20 (Beijing Solarbio Science \& Technology Co., Ltd.), the membranes were incubated overnight at $4^{\circ} \mathrm{C}$ with the primary antibodies to LC3B (1:1,000), beclin-1 (1:2,000), class III PI3K (1:1,000), Bcl-2 $(1: 1,000)$ and $\beta$-actin $(1: 2,000)$, followed by incubation with the appropriate secondary antibody conjugated to $\operatorname{HRP}(1: 7,500)$ at room temperature for $2 \mathrm{~h}$. The membranes were visualized using an enhanced chemiluminescence detection kit (Thermo Fisher Scientific, Waltham, MA, USA) and then exposed to X-ray film (Carestream Health, Xiamen, China). The relative band size was determined by standard scanning densitometry and values were normalized to $\beta$-actin.

MTT assay for cell viability. Cells were seeded at a density of $2 \times 10^{5}$ cells $/ \mathrm{ml}$ in a flat-bottom- 96-well plate. After treatment, MTT solution ( $5.0 \mathrm{~g} / \mathrm{l}$ in PBS) was added to the culture media at a final concentration of $500 \mu \mathrm{g} / \mathrm{ml}$, and the cells were incubated for $4 \mathrm{~h}$ at $37^{\circ} \mathrm{C}$. The supernatant was then discarded, and $150 \mu \mathrm{l}$ dimethyl sulfoxide (Tianjing Dengke Chemical Reagent Co., Ltd.) was added to dissolve the formazan. The absorbance was 

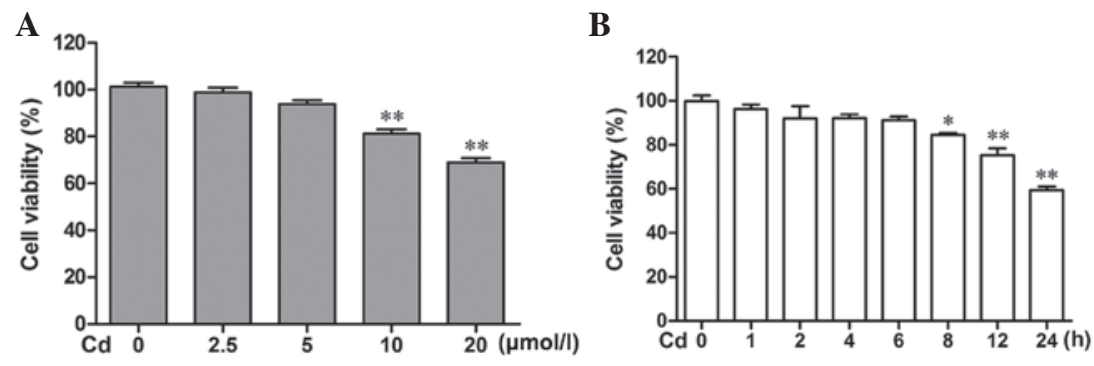

Figure 1. Cd causes a decrease in the cell viability of cerebral cortical neurons. Cerebral cortical neurons were treated with (A) $0-20 \mu \mathrm{mol} / 1 \mathrm{Cd}$ for $24 \mathrm{~h}$ or with (B) $20 \mu \mathrm{mol} / 1 \mathrm{Cd}$ for different durations. Cell viability was measured by the MTT assay. Values are expressed as the mean \pm standard deviation (n=4-6). ${ }^{*} \mathrm{P}<0.05 ;{ }^{* *} \mathrm{P}<0.01$, compared with controls.

A
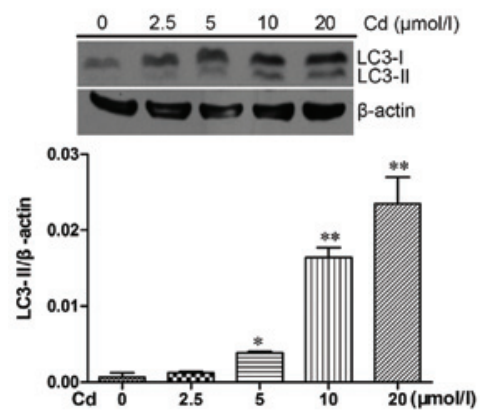

$\mathbf{C}$

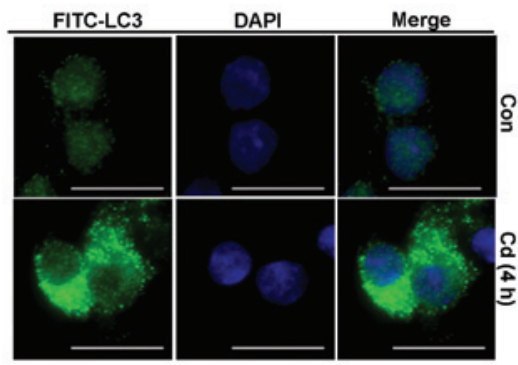

B

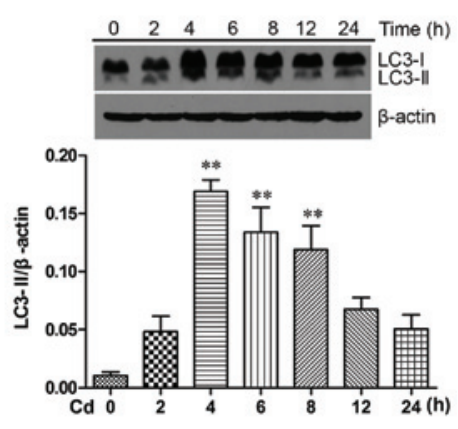

D



$20 \mu \mathrm{mol} / \mathrm{l}(4 \mathrm{~h})$

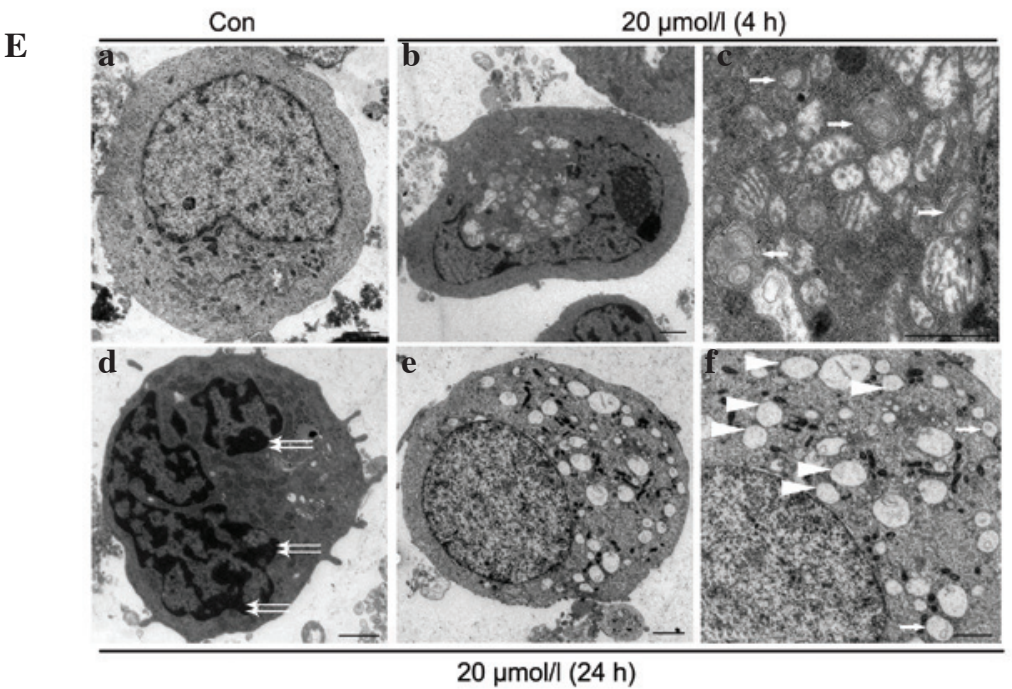

Figure 2. Activation of autophagy in cerebral cortical neurons after Cd treatment. Cerebral cortical neurons were treated with (A) $0-20 \mu \mathrm{mol} / 1 \mathrm{Cd}$ for $4 \mathrm{~h}$ or (B) with $20 \mu \mathrm{mol} / \mathrm{l} \mathrm{Cd}$ for different durations, and cell lysates were analyzed by western blot analysis to detect LC3 expression (upper panels of A and B). Relative band widths were analyzed, quantified and normalized to $\beta$-actin levels (lower panels of A and B). Values are expressed as the mean \pm standard deviation from at least three independent experiments. ${ }^{*} \mathrm{P}<0.05,{ }^{* *} \mathrm{P}<0.01$ vs. control group. (C) Cerebral cortical neurons were treated with $20 \mu \mathrm{mol} / 1 \mathrm{Cd}$ for $4 \mathrm{~h}$ and subjected to indirect immunofluorescence staining (scale bar, $10 \mu \mathrm{m}$ ). (D) Histogram showing the number of cerebral cortical neurons with punctate FITC-LC3 staining totaling $\sim 300$ cells. Values are expressed as the mean \pm standard deviation $\left({ }^{* *} \mathrm{P}<0.01\right)$. (E) Transmission electron microscopy images of cerebral cortical neurons. (a) Control cell; (b and c) cells treated with $20 \mu \mathrm{mol} / 1 \mathrm{Cd}$ for $4 \mathrm{~h}$ at low and high power, respectively. The lower panels show cells treated with $20 \mu \mathrm{mol} / 1 \mathrm{Cd}$ for $24 \mathrm{~h}$ at (d and e) low power and (f) high power. Autophagosomes are indicated by white arrows in (c) and (f), whereas apoptotic changes such as chromatin condensation (white double-headed arrows) and cytoplasmic vacuolization (white arrowheads) are highlighted in (d) and (f), respectively (scale bar, $1 \mu \mathrm{m}$ ). FITC, fluorescein isothiocyanate; LC-3, microtubule-associated protein 1A/1B-light chain 3; Con, control. 
A



C



$\mathbf{E}$

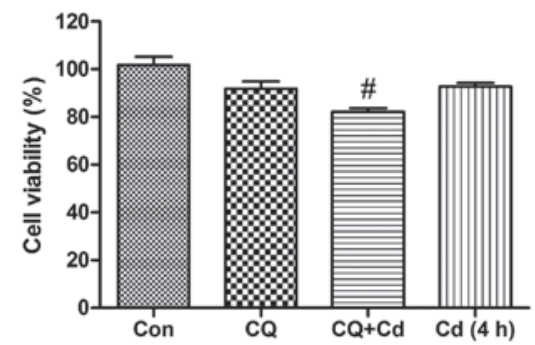

B

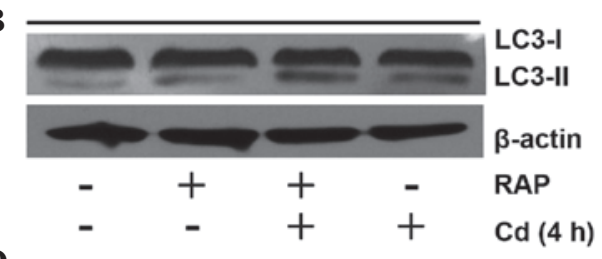

D

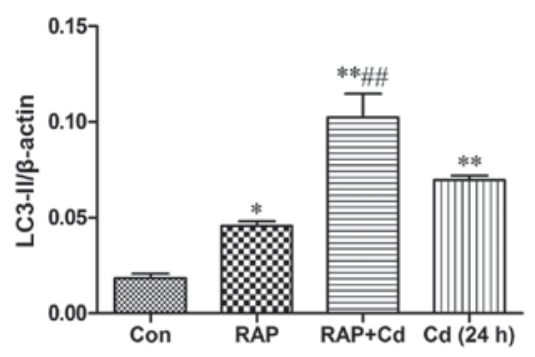

$\mathbf{F}$



Figure 3. Induction of autophagy reduces the Cd-mediated cytotoxicity. (A) Cerebral cortical neurons were pre-treated with $5 \mu \mathrm{mol} / \mathrm{l} \mathrm{CQ}$ for $0.5 \mathrm{~h}$, followed by treatment with $20 \mu \mathrm{mol} / 1 \mathrm{Cd}$ for $4 \mathrm{~h}$, or (B) pre-treated with $100 \mathrm{nmol} / 1 \mathrm{RAP}$ for $24 \mathrm{~h}$, followed by treatment with $20 \mu \mathrm{mol} / 1 \mathrm{Cd}$ for another $24 \mathrm{~h}$. Western blot analysis was then performed to measure LC3 protein expression. The blots were also probed for $\beta$-actin as a loading control. Relative band widths were analyzed, quantified and normalized to $\beta$-actin levels $(\mathrm{n}=3)$. (C and D) MTT assays were performed to determine cell viability following treatment with Cd alone, (E) in combination with CQ or $(\mathrm{F})$ in combination with RAP. Values are expressed as the mean \pm standard deviation $(\mathrm{n}=4-6)$. ${ }^{*} \mathrm{P}<0.05$, ${ }^{* *} \mathrm{P}<0.01$, compared with control group; ${ }^{\#} \mathrm{P}<0.05,{ }^{\# \#} \mathrm{P}<0.01$ compared to the respective Cd group. LC-3, microtubule-associated protein 1A/1B-light chain 3; Rap, rapamycin; $\mathrm{CQ}$, chloroquine; Con, control.

measured at 570/630 $\mathrm{nm}$ using a microplate reader (Sunrise; Tecan Group Ltd, Männedorf, Switzerland).

Statistical analysis. Values are expressed as the mean \pm standard deviation. Significance was assessed by one-way analysis of variance following appropriate transformation to normalized data and equalized variance where necessary. Statistical analysis was performed using SPSS 19.0 (International Business Machines, Armonk, USA). P $<0.05$ was considered to indicate a statistically significant difference between values.

\section{Results}

Cd decreases the viability of cerebral cortical neurons. The effect of $\mathrm{Cd}$ on the viability of cerebral cortical neuron cells was investigated by MTT assays. As shown in Fig. 1A and B, $\mathrm{Cd}$ treatment caused a decrease in cell viability in a dose- and time-dependent manner. $\mathrm{Cd}$ caused a significant decrease in cell viability at 10 and $20 \mu \mathrm{mol} / 1$ when applied for $24 \mathrm{~h}$, compared with that in the control group $(\mathrm{P}<0.01)$. Treatment with $20 \mu \mathrm{mol} / 1 \mathrm{Cd}$ for $0,1,2,4$ and $6 \mathrm{~h}$ had no inhibitory effect. However, 8, 12 and $24 \mathrm{~h}$ after treatment with $20 \mu \mathrm{mol} / 1$ $\mathrm{Cd}$, an inhibitory effect was obvious $(\mathrm{P}<0.05, \mathrm{P}<0.01$ and $\mathrm{P}<0.01$, respectively).

Activation of autophagy in cerebral cortical neurons after $\mathrm{Cd}$ treatment. Autophagy induction in Cd-treated cerebral cortical neuron cells was determined via detection of LC3 using western blot analysis, immunofluorescence staining and TEM. As shown in Fig. 2A, the levels of LC3-II protein increased after $\mathrm{Cd}$ treatment at 10 and $20 \mu \mathrm{mol} / 1(\mathrm{P}<0.01)$. In the case of treatment with $20 \mu \mathrm{mol} / \mathrm{l} \mathrm{Cd}$, there was a significant increase in LC3-II protein levels after treatment for $4 \mathrm{~h}$, $6 \mathrm{~h}(\mathrm{P}<0.01)$ and $8 \mathrm{~h}(\mathrm{P}<0.05)$, but not after shorter $(2 \mathrm{~h})$ or longer (12 and $24 \mathrm{~h}$ ) treatments (Fig. 2B). The distribution of endogenous LC3-II staining in cells prior to and after $4 \mathrm{~h}$ of $\mathrm{Cd}$ treatment was monitored by indirect immunofluorescence staining (Fig. 2C). Specific punctate distribution of endogenous LC3-II was observed in cortical neurons treated with $\mathrm{Cd}$; more dots appeared in Cd-treated neurons than in control neurons (P<0.01; Fig. 2D). Single-membrane vacuoles, whorls of membranous material and other ultra-structures were observed in Cd-treated neurons (4 h), which were not present in control neurons (Fig. 2E; a-c). However, after Cd treatment for $24 \mathrm{~h}$, signs of apoptosis, including chromatin condensation along the nuclear envelope and vacuole formation in the cytoplasm, were also observed (Fig. 2E; d-f). These results indicated that $\mathrm{Cd}$ treatment induced autophagy and apoptosis in cortical neurons.

Induction of autophagy reduces Cd-induced cytotoxicity. Numerous studies have demonstrated that autophagy can serve as a protective response to prevent heavy metal-induced cell death (18). CQ, an inhibitor of autophagy, can inhibit the autophagic process by preventing lysosome-autophagosome 
A

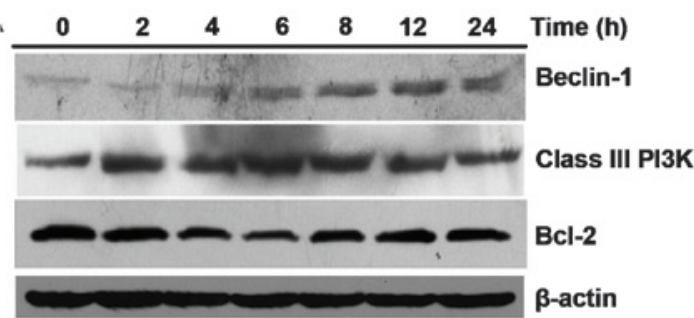

C

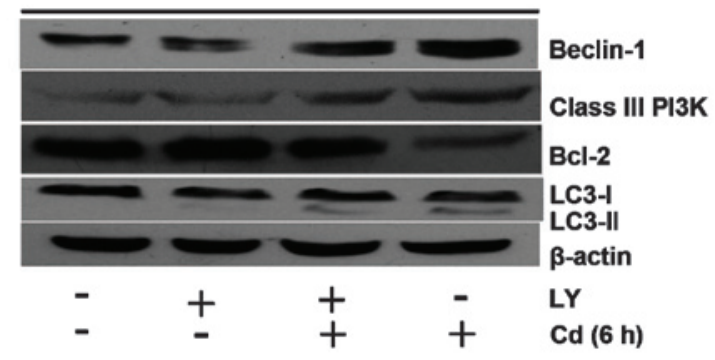

$\mathbf{E}$

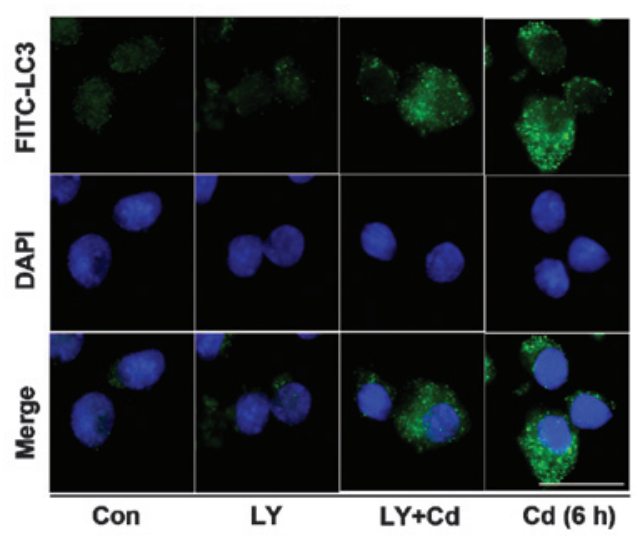

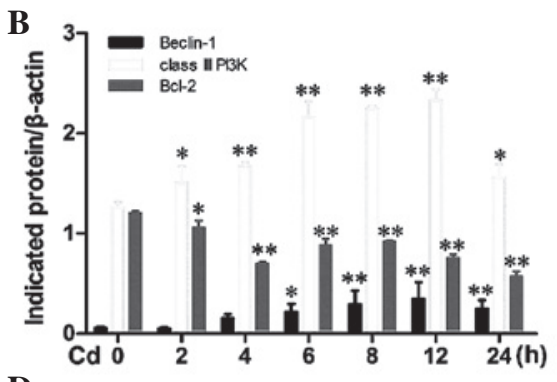

D

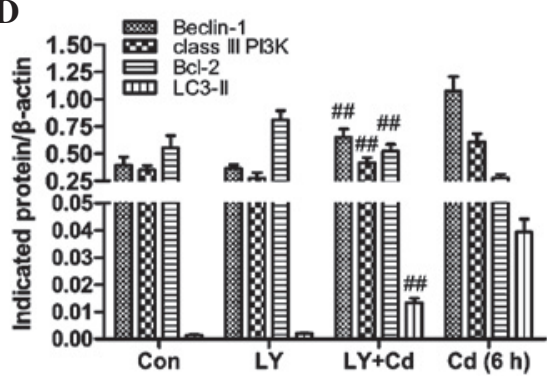

F

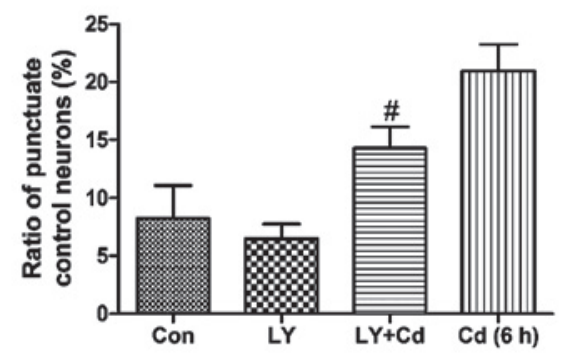

Figure 4. The class III PI3K/beclin-1/Bcl-2 signaling pathway contributes to autophagy activation. (A) Cerebral cortical neurons were treated with $20 \mu$ mol/1 $\mathrm{Cd}$ for various durations and cell lysates were analyzed by western blot with the indicated antibodies. $\beta$-actin was used as a loading control. (B) Indicated proteins from A were semi-quantified using Image Lab software. Values are expressed as the mean \pm standard deviation of results from three independent experiments. ${ }^{*} \mathrm{P}<0.05,{ }^{* *} \mathrm{P}<0.01$ vs. control group. (C) Cortical neurons were harvested following $6 \mathrm{~h}$ of treatment with (or without) $20 \mu \mathrm{mol} / 1 \mathrm{Cd}$ in the presence or absence of $20 \mu \mathrm{mol} / 1 \mathrm{LY}$. Cell lysates were analyzed by immunoblot assay with indicative antibodies with $\beta$-actin used as a loading control. (D) The optical densities of the respective protein bands in $\mathrm{C}$ were analyzed using Image Lab and normalized to the loading control ( $\beta$-actin). Values are expressed as the mean \pm standard deviation of date from three independent experiments. ${ }^{\# \#} \mathrm{P}<0.01$ compared to the Cd group. (E) Immunofluorescence analysis. Cortical neurons were treated for $6 \mathrm{~h}$ with (or without) $20 \mu \mathrm{mol} / 1 \mathrm{Cd}$ in the presence or absence of $20 \mu \mathrm{mol} / 1 \mathrm{LY}$ and incubated with anti-LC3, FITC-conjugated secondary antibody, and then DAPI to stain the nuclei (scale bar, $10 \mu \mathrm{m}$ ). (F) Quantified cerebral cortical neurons with punctate FITC-LC3 from E; values are expressed as mean \pm standard deviation. ${ }^{*} \mathrm{P}<0.05$ compared to the Cd group. Bcl-2, B-cell lymphoma 2; PI3K, phosphoinositide 3 kinase; LC-3, microtubule-associated protein 1A/1B-light chain 3; Ly, PI3K inhibitor LY294002; Con, control; FITC, fluorescein isothiocyanate.

fusion, which leads to a remarkable accumulation of autophagic vacuoles (19). As LC3-II is associated with autophagic vacuoles, CQ treatment also induces intense LC3-II accumulation (20). RAP, an inducer of autophagy, has been shown to induce autophagy by inhibiting the mammalian target of rapamycin pathway (21). Thus, CQ and RAP were employed in the present study to detect the effect of autophagy on Cd-induced cytotoxicity. The results indicated that CQ and RAP markedly increased LC3-II production (Fig. 3A-D). An MTT assay was used to monitor the effects of CQ and RAP on cell viability. Treatment with CQ or RAP alone did not significantly inhibit cell viability, but in combination with Cd, CQ significantly augmented the decrease in cell viability observed with Cd alone (Fig. 3E). However, RAP markedly reduced the Cd-induced decrease in cell viability (Fig. 3F), confirming that Cd-mediated autophagy has a cytoprotective effect.
The class III PI3K/beclin-1/Bcl-2 signaling pathway contributes to autophagy activation. To investigate the signaling pathways involved in the induction of autophagy in Cd-treated cerebral cortical neuron cells, class III PI3K, beclin-1 and Bcl-2 were examined by immunoblot analysis. In cells treated with $20 \mu \mathrm{mol} / 1 \mathrm{Cd}$ for $0-24 \mathrm{~h}$ (Fig. $4 \mathrm{~A}$ and $\mathrm{B})$, the protein levels of beclin-1 and class III PI3K were significantly upregulated and peaked at $12 \mathrm{~h}$ after $\mathrm{Cd}$ treatment. Bcl-2 levels were initially decreased and then slightly increased; overall, however, Bcl-2 levels exhibited a downward trend within $24 \mathrm{~h}$. The results suggested that the class III PI3K/beclin-1/Bcl-2 pathway may be involved in the autophagy of cerebral cortical neuronal cells.

To further explore the association between the class III PI3K/beclin-1/Bcl-2 pathway and autophagy, LY, a PI3K inhibitor, was applied during Cd treatment. The results demonstrated that a concentration of $20 \mu \mathrm{mol} / 1 \mathrm{LY}$ significantly 
decreased the expression of beclin-1, class III PI3K and LC3-II and promoted Bcl-2 protein expression in Cd-treated cerebral cortical neurons (Fig. 4C and D). Concomitantly, autophagocytosis was also obviously decreased after treatment with Cd and LY compared to that following treatment with Cd alone (Fig. 4C-F). These results indicated that the decreased expression of beclin-1 and class III PI3K or the increased expression of $\mathrm{Bcl}-2$ by a PI3K inhibitor inhibits autophagy in $\mathrm{Cd}$-injured cerebral cortical neurons.

\section{Discussion}

$\mathrm{Cd}$ is a neurotoxic metal known to be a major environmental contaminant. The potential impact of $\mathrm{Cd}$ on the nervous system has long been recognized (22). A recent study by our group demonstrated that exposure of PC-12 cells to $\mathrm{Cd}$ stimulates autophagy, which can delay the occurrence of apoptosis (23). The present study provided further evidence that $\mathrm{Cd}$ can induce cytoprotective autophagy by activating the class III $\mathrm{PI} 3 \mathrm{~K} /$ beclin-1/Bcl-2 signaling pathway in rat cerebral cortical neurons.

Recent reports demonstrated that the autophagy process is important for the cellular response to oxidative stress, as it helps to conserve cellular energy as well as to limit damaged proteins and organelles that amplify toxic signals (24-26); therefore, the present study hypothesized that $\mathrm{Cd}$-induced autophagy is a housekeeping process that protects neurons from damage at the early stage of $\mathrm{Cd}$ exposure. This hypothesis was verified by the observed CQ-mediated inhibition of autophagy and decrease in cell viability, as well as the RAP-induced activation of autophagy and recovery of cell viability. These results indicated that cerebral cortical neurons can adapt to handle $\mathrm{Cd}$-induced stress through the removal and recycling of damaged proteins and organelles. Similar results were also found following Cd treatment in hematopoietic stem cells (27), lung epithelial fibroblasts (28), rat kidney NRK-52E cells (29) and proximal convoluted tubule cells (30), but not in mesangial cells (31) and skin epidermal cells (32) treated with $\mathrm{Cd}$. The differences in autophagy induction by $\mathrm{Cd}$ in these studies may be due to differential $\mathrm{Cd}$ concentration and duration of exposure as well as variability in the metabolic state and cell type studied. In the present study, autophagy did not completely protect cells from damage caused by $\mathrm{Cd}$ treatment as demonstrated by the MTT assay. Other processes that may be involved in the $\mathrm{Cd}$-induced reduction in cell viability are damage to DNA-repairing systems (33) and activation of P53, which leads to cell cycle arrest and the induction of cell death (34). In the late stages of autophagy, the features of apoptosis, including chromatin condensation and cytoplasmic vacuolization, were observed using TEM, indicating that $\mathrm{Cd}$ causes autophagy as well as apoptosis, depending on the CD concentration and duration of treatment. It may be postulated that upon initial exposure to $\mathrm{Cd}$, autophagy is induced, but at later stages, when the damage becomes irreversible, apoptosis takes over. Further studies are required to investigate the association between $\mathrm{Cd}$ treatment, autophagy and apoptosis.

Various signaling pathways are thought to be involved in regulating autophagy induced by $\mathrm{Cd}(28,32,35)$, but the molecular mechanisms that govern $\mathrm{Cd}$-induced autophagy have yet to be fully elucidated. This inspired the present study to inves- tigate which signaling pathways are responsible for $\mathrm{Cd}$-induced autophagy in cerebral cortical neurons. In the present study, it was demonstrated that class III PI3K/beclin-1/Bcl-2 signaling has a major role in regulating $\mathrm{Cd}$-induced autophagy. Of note, the decrease of $\mathrm{Bcl}-2$ expression preceded the elevation of beclin-1, suggesting that a decrease in Bcl-2 facilitates the release of beclin-1, allowing it to form a complex with class III $\mathrm{PI} 3 \mathrm{~K}$, which is required for regulating autophagy $(36,37)$. The present study further confirmed that disrupting Bcl-2/beclin-1 interactions may be a mechanism used by cells to promote autophagy and cell survival during conditions of stress $(38,39)$. However, the results showed that after a rapid decline during the first hours of $\mathrm{Cd}$ treatment, Bcl-2 levels began to rise again after longer durations of $\mathrm{Cd}$ treatment. One of the possible explanations for this is that cells initiate compensatory mechanisms under stressful conditions (6). Further studies are required to elucidate the detailed mechanism of how Bcl-2 regulates $\mathrm{Cd}$-induced autophagy.

In conclusion, the results of the present study suggested that $\mathrm{Cd}$ induces a decrease in cell viability and initiates autophagy (in the early stages) in rat cerebral cortical neurons. The results also suggested that autophagy may have an important protective role in $\mathrm{Cd}$-induced cytotoxicity by activating class III PI3K/beclin-1/Bcl-2 signaling pathways. These results provided essential preliminary data for the further assessment of Cd-induced neurotoxicity.

\section{Acknowledgements}

The present study was supported by the National Natural Science Foundation of China (nos. 31302058, 31101866 and 31172373), a Project Funded by the Priority Academic Program Development of Jiangsu Higher Education Institutions (PAPD) and the Joint Foundation of Guizhou Province [LKB (2013) 02].

\section{References}

1. Hsieh MJ, Tsai TL, Hsieh YS, Wang CJ and Chiou HL: Dioscin-induced autophagy mitigates cell apoptosis through modulation of PI3K/Akt and ERK and JNK signaling pathways in human lung cancer cell lines. Arch Toxicol 87: 1927-1937, 2013.

2. Levine B and Yuan J: Autophagy in cell death: an innocent convict? J Clin Invest 115: 2679-2688, 2005.

3. Kang M, Jeong CW, Ku JH, Kwak C and Kim HH: Inhibition of autophagy potentiates atorvastatin-induced apoptotic cell death in human bladder cancer cells in vitro. Int J Mol Sci 15: 8106-8121, 2014.

4. Kang R, Zeh H, Lotze $\mathrm{M}$ and Tang D: The Beclin 1 network regulates autophagy and apoptosis. Cell Death Differ 18: 571-580, 2011.

5. Funderburk SF, Wang QJ and Yue Z: The Beclin 1-VPS34 complex-at the crossroads of autophagy and beyond. Trends Cell Biol 20: 355-362, 2010.

6. Maiuri MC, Le Toumelin G, Criollo A, et al: Functional and physical interaction between Bcl-XL and a BH3-like domain in Beclin-1. EMBO J 26: 2527-2539, 2007.

7. He C and Levine B: The beclin 1 interactome. Curr Opin Cell Biol 22: 140-149. 2010.

8. Levine B and Kroemer G: Autophagy in the pathogenesis of disease. Cell 132: 27-42, 2008.

9. Muneer S, Hakeem KR, Mohamed R and Lee JH: Cadmium toxicity induced alterations in the root proteome of green gram in contrasting response towards iron supplement. Int J Mol Sci 15: 6343-6355, 2014.

10. Łukawski K, Nieradko B and Sieklucka-Dziuba M: Effects of cadmium on memory processes in mice exposed to transient cerebral oligemia. Neurotoxicol Teratol 27: 575-584, 2005. 
11. Curtis JT, Hood AN, Chen Y, Cobb GP and Wallace DR: Chronic metals ingestion by prairie voles produces sex-specific deficits in social behavior: An animal model of autism. Behav Brain Res 213: 42-49, 2010.

12. Mascagni R, Consonni D, Bregante G, Chiappino G and Toffoletto F: Olfactory function in workers exposed to moderate airborne cadmium levels. Neurotoxicology 24: 717-724, 2003.

13. Fernández-Pérez B, Caride A, Cabaleiro T and Lafuente A: Cadmium effects on $24 \mathrm{~h}$ changes in glutamate, aspartate, glutamine, GABA and taurine content of rat striatum. J Trace Elem Med Biol 24: 212-218, 2010.

14. Minami A, Takeda A, Nishibaba D, Takefuta S and Oku N: Cadmium toxicity in synaptic neurotransmission in the brain. Brain Res 894: 336-339, 2001.

15. López E, Figueroa S, Oset-Gasque MJ and González MP: Apoptosis and necrosis: Two distinct events induced by cadmium in cortical neurons in culture. Brit J Pharmacol 138: 901-911, 2003

16. Yuan Y, Jiang CY, Xu H, et al: Cadmium-induced apoptosis in primary rat cerebral cortical neurons culture is mediated by a calcium signaling pathway. PloS One 8: e64330, 2013.

17. Yan Y, Bian JC, Zhong LX, Zhang Y, Sun Y and Liu ZP Oxidative stress and apoptotic changes of rat cerebral cortical neurons exposed to cadmium in vitro. Biomed Environ Sci 25 : 172-181, 2012

18. Chiarelli R and Roccheri MC: Heavy metals and metalloids as autophagy inducing agents: Focus on cadmium and arsenic Cells 1: 597-616, 2012.

19. Zaidi AU, McDonough JS, Klocke BJ, et al: Chloroquine-induced neuronal cell death is p53 and Bcl-2 family-dependent but caspase-independent. J Neuropathol Exp Neurol 60: 937-945, 2001.

20. Geng Y, Kohli L, Klocke BJ and Roth KA: Chloroquine-induced autophagic vacuole accumulation and cell death in glioma cells is p53 independent. Neuro Oncol 12: 473-481, 2010.

21. Klionsky DJ, Abeliovich H, Agostinis P, et al: Guidelines for the use and interpretation of assays for monitoring autophagy in higher eukaryotes. Autophagy 4: 151-175, 2008.

22. Kim SM, Park JG, Baek WK, et al: Cadmium specifically induces MKP-1 expression via the glutathione depletion-mediated p38 MAPK activation in C6 glioma cells. Neurosci Lett 440: 289-293, 2008

23. Wang Q, Zhu J, Zhang K, et al: Induction of cytoprotective autophagy in PC-12 cells by cadmium. Biochem Biophys Res Commun 438: 186-192, 2013

24. Jisun L, Samantha G and Jianhua Z: Autophagy, mitochondria and oxidative stress: Cross-talk and redox signalling. Biochem J 441: 523-540, 2012

25. Benavides GA, Liang Q, Dodson M, Darley-Usmar V and Zhang J: Inhibition of autophagy and glycolysis by nitric oxide during hypoxia-reoxygenation impairs cellular bioenergetics and promotes cell death in primary neurons. Free Radic Bio Med 65 $1215-1228,2013$
26. Duan WJ, Liu FL, He RR, et al: Autophagy is involved in the effects of resveratrol on prevention of splenocyte apoptosis caused by oxidative stress in restrained mice. Mol Nutr Food Res 57: 1145-1157, 2013.

27. Di Gioacchino M,Petrarca C, Perrone A, Martino S, Esposito DL, Lotti LV and Mariani-Costantini R: Autophagy in hematopoietic stem/progenitor cells exposed to heavy metals. Autophagy 4: 537-539, 2008.

28. Lim SC, Hahm KS, Lee SH and Oh SH: Autophagy involvement in cadmium resistance through induction of multidrug resistance-associated protein and counterbalance of endoplasmic reticulum stress WI38 lung epithelial fibroblast cells. Toxicology 276: 18-26, 2010.

29. Kato H, Katoh $\mathrm{R}$ and Kitamura M: Dual regulation of cadmium-induced apoptosis by mtorcl through selective induction of IRE1 branches in unfolded protein response. PloS One 8: e64344, 2013.

30. Chargui A, Zekri S, Jacquillet G, et al: Cadmium-induced autophagy in rat kidney: an early biomarker of subtoxic exposure. Toxicol Sci 121: 31-42, 2011

31. Wang SH, Shih YL, Ko WC, Wei YH and Shih CM Cadmium-induced autophagy and apoptosis are mediated by a calcium signaling pathway. Cell Mol Life Sci 65: 3640-3652, 2008.

32. Son YO, Wang X, Hitron JA, et al: Cadmium induces autophagy through ROS-dependent activation of the LKB1-AMPK signaling in skin epidermal cells. Toxicol Appl Pharmacol 255: 287-296, 2011.

33. Giaginis C, Gatzidou E and Theocharis S: DNA repair systems as targets of cadmium toxicity. Toxicol Appl Pharmacol 213: 282-290, 2006

34. Liu ZM, Chen GG, Vlantis A, Tse G, Shum C and Van Hasselt C: Calcium-mediated activation of PI3K and p53 leads to apoptosis in thyroid carcinoma cells. Cell Mol Life Sci 64: 1428-1436, 2007.

35. Yang LY, Wu KH, Chiu WT, Wang SH and Shih CM: The cadmium-induced death of mesangial cells results in nephrotoxicity. Autophagy 5: 571-572, 2009.

36. Simonsen A and Tooze SA: Coordination of membrane events during autophagy by multiple class III PI3-kinase complexes. J Cell Biol 186: 773-782, 2009.

37. Levine B, Sinha S and Kroemer G: Bcl-2 family members: dual regulators of apoptosis and autophagy. Autophagy 4: 600-606, 2008.

38. Degenhardt K, Mathew R, Beaudoin B, et al: Autophagy promotes tumor cell survival and restricts necrosis, inflammation and tumorigenesis. Cancer Cell 10: 51-64, 2006.

39. Fung C, Lock R, Gao S, Salas E and Debnath J: Induction of autophagy during extracellular matrix detachment promotes cell survival. Mol Biol Cell 19: 797-806, 2008. 